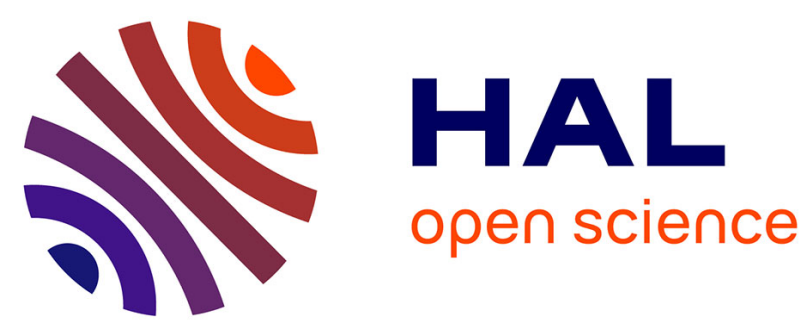

\title{
Mechanosynthesis and Multiferroic Properties of the BiFeO3-BiMnO3-PbTiO3 Ternary System along its Morphotropic Phase Boundary
}

Carmen M. Fernandez-Posada, Harvey Amorín, Covadonga Correas, Octavio Peña, Miguel Algueró, Alicia Castro

\section{To cite this version:}

Carmen M. Fernandez-Posada, Harvey Amorín, Covadonga Correas, Octavio Peña, Miguel Algueró, et al.. Mechanosynthesis and Multiferroic Properties of the BiFeO3-BiMnO3-PbTiO3 Ternary System along its Morphotropic Phase Boundary. Journal of Materials Chemistry C, 2015, 3 (10), pp.22552265. 10.1039/C4TC02053G . hal-01196650

\section{HAL Id: hal-01196650}

https://hal-univ-rennes1.archives-ouvertes.fr/hal-01196650

Submitted on 10 Sep 2015

HAL is a multi-disciplinary open access archive for the deposit and dissemination of scientific research documents, whether they are published or not. The documents may come from teaching and research institutions in France or abroad, or from public or private research centers.
L'archive ouverte pluridisciplinaire HAL, est destinée au dépôt et à la diffusion de documents scientifiques de niveau recherche, publiés ou non, émanant des établissements d'enseignement et de recherche français ou étrangers, des laboratoires publics ou privés. 


\section{Mechanosynthesis and Multiferroic Properties of the $\mathrm{BiFeO}_{3}-\mathrm{BiMnO}_{3}-\mathrm{PbTiO}_{3}$}

\section{Ternary System along its Morphotropic Phase Boundary}

Carmen M. Fernández-Posada, ${ }^{a}$ Harvey Amorín, ${ }^{* a}$ Covadonga Correas, ${ }^{a}$ Octavio Peña,${ }^{b}$ Miguel Algueróa and Alicia Castro ${ }^{\mathrm{a}}$

a Instituto de Ciencia de Materiales de Madrid (ICMM), CSIC. Cantoblanco, 28049 Madrid, Spain.E-mail: hamorin@icmm.csic.es

b Institut des Sciences Chimiques de Rennes (ISCR), UMR 6226, Université de Rennes 1, 35042 Rennes, France

A highly topical set of materials are those $\mathrm{ABO}_{3}$ perovskite oxides, in which multiferroicity is chemically engineered by placing ferroelectrically and magnetically active cations in $A$ and $B$-site, respectively. This is the case of the $\mathrm{BiFeO}_{3}$ and $\mathrm{BiMnO}_{3}$ perovskites, and also of the solid solutions they form with $\mathrm{PbTiO}_{3}$. Interest in these binary systems is fostered by the presence of distinctive morphotropic phase boundaries (MPBs); multiferroic in the case of $\mathrm{BiFeO}_{3}-\mathrm{PbTiO}_{3}$, for which a high magnetoelectric response has been anticipated. Here, new compositions belonging to the ternary system $\mathrm{BiFeO}_{3}-\mathrm{BiMnO}_{3}-\mathrm{PbTiO}_{3}$, and specifically along the line that joins the former MPBs, have been prepared by mechanosynthesis to accomplish a thorough analysis of their multiferroic nature. Nanocrystalline powders with perovskite-type structure were obtained in the entire range of compositions, which all exhibited polymorphic phase coexistence allowing a line of MPBs to be established. The variation of the perovskite structural characteristics along this line has been defined, and correlated with those of the magnetic and electrical properties. A set of novel and promising multiferroic materials has been found for $\mathrm{BiFeO}_{3}$ rich compositions.

Keywords: Multiferroics; perovskite oxides; mechanosynthesis; structural characterization; magnetic behaviour; ferroelectric behaviour 


\section{Introduction}

Multiferroic magnetoelectric materials have become the focus of intensive research, driven by potential applications in novel multifunctional devices, such as spintronics, sensors, and perhaps the most appealing, the next generation of non-volatile memories. ${ }^{1,2}$ The interest in these materials is growing rapidly and focuses in the search of novel approaches to obtain multiferroics with room-temperature (RT) magnetoelectricity. ${ }^{3,4}$ One of the most promising approaches is the engineering of the functionality on a site-by-site basis in systems such as $\mathrm{ABO}_{3}$ perovskites. In this structure, one can make use of the stereochemical activity of an $A$ site cation with lone pair (i.e., $6 \mathrm{~s}^{2}$ electrons in $\mathrm{Bi}^{3+}$ or $\mathrm{Pb}^{2+}$ ) to induce the required distortion for ferroelectricity, while magnetism can be achieved with the incorporation of a magnetic $B$ site cation. ${ }^{5}$ This is the case of $\mathrm{BiMO}_{3}(\mathrm{M}=\mathrm{Cr}, \mathrm{Mn}, \mathrm{Fe}, \mathrm{Co}, \mathrm{Ni})$, although only a few of these Bi-containing perovskites can be prepared by conventional methods, and usually highpressure techniques are required. ${ }^{6}$ Among them, $\mathrm{BiFeO}_{3}$ is the most topical multiferroic material, for it is perhaps the only compound that shows both magnetic ordering and proper ferroelectricity at $\mathrm{RT}^{7}$ Another topical material is $\mathrm{BiMnO}_{3}$, the only oxide among the abovementioned that has a true ferromagnetic state with ordering temperature of $T_{C} \sim 100 \mathrm{~K}$, yet there is no consensus about its ferroelectricity. ${ }^{8-10}$

A number of studies have come forth in the last years that aimed at enhancing the stability of $\mathrm{BiFeO}_{3}$ and $\mathrm{BiMnO}_{3}$ perovskites, while maintaining or even enhancing its properties, by doping or the preparation of solid solutions. ${ }^{11-14}$ In particular, attention has been put on the solid solutions they form with the tetragonal $\mathrm{PbTiO}_{3}$ perovskite. Interest in these binary systems $\left(\mathrm{BiFeO}_{3}-\mathrm{PbTiO}_{3}\right.$ and $\left.\mathrm{BiMnO}_{3}-\mathrm{PbTiO}_{3}\right)$ is fostered by the presence of morphotropic phase boundaries (MPBs) which are potentially multiferroics. Ferroelectric materials at these phase instability regions exhibit an enhancement of properties like dielectric permittivity and piezoelectric coefficients that makes them of special interest for applications. ${ }^{15}$ Moreover; 
high magnetoelectric response has been anticipated for such multiferroic MPBs originated from electric field-driven phase-change phenomena. ${ }^{16}$

In the case of $\mathrm{BiFeO}_{3}-\mathrm{PbTiO}_{3}$, the MPB is characterized by coexistence of rhombohedral $R 3 \mathrm{c}$ and tetragonal $\mathrm{P} 4 \mathrm{~mm}$ polymorphs for compositions around $0.7 \mathrm{BiFeO}_{3}-0.3 \mathrm{PbTiO}_{3},{ }^{17-19}$ which would be then isostructural with the edge ferroelectric oxides of the binary system. The extent of $R 3 \mathrm{c} / \mathrm{P} 4 \mathrm{~mm}$ phase coexistence region is dependent on the processing conditions and thermal history, which seems to be a characteristic feature of the system associated with its degeneracy at the MPB. ${ }^{20}$ Moreover, evidences of an intermediate MPB phase that bridges the $R 3 \mathrm{c}$ and $\mathrm{P} 4 \mathrm{~mm}$ phases were provided by electron diffraction, ${ }^{21}$ and latest Rietveld refinements of X-ray diffraction (XRD) data have indicated it to be monoclinic $C c{ }^{22}$

A number of reports have addressed the magnetic properties across its MPB..$^{23-25}$ Both, Gtype antiferromagnetic (AFM) spin configuration and the Néel temperature $\left(\mathrm{T}_{\mathrm{N}}\right)$ were found dependent on the crystal symmetry, the latter being at $\sim 473 \mathrm{~K}$ for the $R 3 c$ phase and below RT ( $210 \mathrm{~K})$ for the $P 4 m m$ one. Moreover, monoclinic phase also presents a second magnetic anomaly in their susceptibility below $\mathrm{T}_{\mathrm{N}}$, which has been described as a spin reorientation transition between two G-type AFM states, wherein the canted-ferromagnetic component undergoes a spin flop. ${ }^{26}$ Outstanding ferroelectric properties have been reported at the MPB. The occurrence of phase-change between the rhombohedral (or monoclinic) and tetragonal polymorphs under high electric field results in a remnant polarization of $63 \mu \mathrm{C} \mathrm{cm}^{-2}$ (perhaps the highest reported for a ceramic material) with a relatively low coercive field. ${ }^{27,28}$ Strong magnetoelectric responses could be thus anticipated, associated with this phase-change phenomena, even so the ferromagnetic component is weak.

For the $\mathrm{BiMnO}_{3}-\mathrm{PbTiO}_{3}$, the MPB region has been set around $0.4 \mathrm{BiMnO}_{3}-0.6 \mathrm{PbTiO}_{3},{ }^{29}$ and separates the tetragonal $\mathrm{P} 4 \mathrm{~mm}$ and orthorhombic Pnma polymorphs. ${ }^{30}$ However, very few reports have addressed their magnetic and ferroelectric properties across the MPB. Spin- 
canted AFM order with very low ordering temperature of $\sim 11 \mathrm{~K}$ was suggested which would originate from the superexchange interaction between $\mathrm{Mn}^{3+}$ cations mediated by the oxygen, forming a net of interacting ions diluted by modification with the nonmagnetic $\mathrm{PbTiO}_{3}{ }^{29} \mathrm{In}$ contrast, the ferroelectric characterization has been challenging due to conductivity issues. ${ }^{31}$

In this work, we present a study of the $\mathrm{BiFeO}_{3}-\mathrm{BiMnO}_{3}-\mathrm{PbTiO}_{3}$ ternary system, in the search of novel multiferroic MPBs that may show RT magnetoelectricity. Specifically, a number of compositions along the whole line connecting the respective MPBs of the binary systems (i.e., from $0.7 \mathrm{BiFeO}_{3}-0.3 \mathrm{PbTiO}_{3}$ to $0.4 \mathrm{BiMnO}_{3}-0.6 \mathrm{PbTiO}_{3}$ ), as illustrated in Fig. 1 , were investigated. Mechanochemical route was chosen for the synthesis, which has been demonstrated optimal for the preparation of both $\mathrm{BiFeO}_{3}, \mathrm{BiMnO}_{3}$, and their solid solutions

with $\mathrm{PbTiO}_{3}{ }^{9,18,30}$ Results here clearly show that coexistence of polymorphic phases takes place along the whole line, which is thus a line of MPBs. Results from the dielectric and magnetic characterization allow accomplishing a thorough analysis of the actual multiferroic nature of the line of MPBs along the ternary system.

\section{Experimental section}

\subsection{Synthesis of nanopowders and ceramic processing}

The compositions respond to the general formula $\mathrm{Bi}_{0.7-0.3 x} \mathrm{~Pb}_{0.3(1+x)} \mathrm{Mn}_{0.4 x} \mathrm{Fe}_{0.7(1-x)} \operatorname{Ti}_{0.3(1+x)} \mathrm{O}_{3}$, obtained from $x\left(0.4 \mathrm{BiMnO}_{3}-0.6 \mathrm{PbTiO}_{3}\right)-(1-x)\left(0.7 \mathrm{BiFeO}_{3}-0.3 \mathrm{PbTiO}_{3}\right)$, with $x$ equals to 0 , $0.15,0.25,0.325,0.425,0.5,0.575,0.675,0.75,0.85,1$, as illustrated in Fig. 1. Powdered samples were prepared by mechanochemical route from stoichiometric mixtures of analytical grade $\mathrm{Bi}_{2} \mathrm{O}_{3}, \mathrm{Fe}_{2} \mathrm{O}_{3}, \mathrm{Mn}_{2} \mathrm{O}_{3}, \mathrm{PbO}$ and $\mathrm{TiO}_{2}$. Details of the procedure and of the mechanisms taking place during the mechanical treatments can be found elsewhere. ${ }^{18,30}$ Initial mixtures were homogenized in an agate mortar, and then $10 \mathrm{~g}$ of each mixture were mechanically treated in a Pulverisette 6 (Fritsch) planetary mill operating at $300 \mathrm{rpm}$. Grinding vessels of 
$250 \mathrm{~cm}^{3}$ with seven balls of $2 \mathrm{~cm}$ in diameter and $63 \mathrm{~g}$ in weight each (powder-to-ball weight ratio of 1:44) were used all made of tungsten carbide (WC). After mechanical treatments and for specific studies, the powders were thermally treated at $950{ }^{\circ} \mathrm{C}$ for $2 \mathrm{~h}$ followed by fast cooling (quenching) in air down to RT to increase crystallinity.

Ceramic materials of the whole range of compositions were prepared by hot-pressing of the nanocrystalline powders obtained by mechanosynthesis. Powders were uniaxially pressed into $12 \mathrm{~mm}$ diameter discs and hot-pressing was carried out in the temperature range between 850 and $950{ }^{\circ} \mathrm{C}$ for $1 \mathrm{~h}$ under $60 \mathrm{MPa}$, using heating and cooling rates of $3{ }^{\circ} \mathrm{C} \mathrm{min}{ }^{-1}$. Density of the samples was measured by Archimedes's method in distilled water after polishing.

\subsection{Structural and microstructural characterization}

The phase evolution during the mechanical treatment and after the thermal treatments was followed by powder X-ray diffraction (XRD) with a Bruker AXS D8 Advance diffractometer in the range of $15^{\circ}$ to $70^{\circ}(2 \theta)$, in steps of $0.05^{\circ}$ and counting time of 1.5 s per step. $\mathrm{Cu} \mathrm{K \alpha}$ doublet $(\lambda=1.5418 \AA)$ was used in these experiments. Lattice parameters, corresponding to samples mechanosynthesized and subsequently thermally treated at $950{ }^{\circ} \mathrm{C}$, were calculated from XRD data using a least-square refinement method (CELREF). ${ }^{32}$

The morphology of the nanopowders was examined by transmission electron microscopy (TEM) using a Philips CM20FEG microscope working at $200 \mathrm{kV}$. Specimens for TEM were prepared from suspensions ultrasonically dispersed in ethanol, a drop of which was placed on a copper grid covered with a holey carbon film for observation. The microstructure of the ceramic samples was examined by field emission scanning electron microscopy (FE-SEM, FEI Nova NanoSEM 230 operating between 5 and $15 \mathrm{kV}$ and equipped with an OXFORD INCA 250 electron dispersive X-ray (EDX) detector), on samples polished, thermally etched at $800{ }^{\circ} \mathrm{C}$ for $20 \mathrm{~min}$, and then quenched down to $\mathrm{RT}$ in air to reveal the grain boundaries. 
X-ray photoelectron spectroscopy (XPS) analysis was carried out using a SPECS GmbH spectrometer operating in the constant analyzer energy mode. A monochromatic Al source $(1486.74 \mathrm{eV})$ was used with power of $200 \mathrm{~W}$ and voltage of $12 \mathrm{kV}$. Pass energy of 75 and 25 $\mathrm{eV}$ were used for acquiring survey and high resolution spectra, respectively. Survey data was acquired from kinetic energies of 1496-400 eV with an energy step of $1 \mathrm{eV}$ and $100 \mathrm{~ms}$ dwell time per point. High resolution scans were taken around the emission lines of interest with $0.1 \mathrm{eV}$ steps and $100 \mathrm{~ms}$ dwell time per point. SpecsLab Version 2.78 software was used for spectrometer control and data handling. The energetic position of the $\mathrm{C} 1 \mathrm{~s}$ emission line (binding energy of $284.6 \mathrm{eV}$ ) was used to calibrate the energy scale of the spectra.

\subsection{Magnetic and dielectric characterization}

Magnetic measurements were carried out on powder samples with a Quantum Design MPMS-XL5 SQUID magnetometer between 2 and $400 \mathrm{~K}$ under zero field cooling (ZFC) and field cooling (FC) conditions to evaluate the magnetic behavior of the compound and to identify the magnetic transitions. First, samples were cooled down to $2 \mathrm{~K}$ under zero field, and then, a magnetic field of 500 Oe was applied and maintained during a following heating (ZFC) and cooling (FC) cycle. Isothermal magnetization measurements $\mathrm{M}(\mathrm{H})$ were recorded at 2 and $300 \mathrm{~K}$, with increasing and decreasing fields between $-50 \mathrm{kOe}$ and $+50 \mathrm{kOe}$.

Electrical characterization was carried out on ceramic discs, on which Ag electrodes were painted and sintered at $800{ }^{\circ} \mathrm{C}$. The temperature dependence of the dielectric permittivity and losses $(\tan \delta)$ were dynamically measured under heating/cooling cycles at $1.5^{\circ} \mathrm{C} \mathrm{min}{ }^{-1}$, with a HP4284A precision LCR Meter in the frequency range between $100 \mathrm{~Hz}$ and $1 \mathrm{MHz}$.

\section{$3 \quad$ Results and discussion}

\subsection{Synthesis and structural characterization}


The process of mechanosynthesis of the binary systems $\mathrm{BiFeO}_{3}-\mathrm{PbTiO}_{3}$ and $\mathrm{BiMnO}_{3}-\mathrm{PbTiO}_{3}$ has already been described to take place in two steps; ${ }^{18,30}$ the starting reagents are readily amorphized during the first hours of mechanical treatment along with severe particle size reduction, stage after which perovskite formation takes place with increasing milling time. The perovskite could successfully be isolated as a single phase after 24 and $18 \mathrm{~h}$ of milling for compositions at the $\mathrm{MPBs}$ of $\mathrm{BiFeO}_{3}-\mathrm{PbTiO}_{3}$ and $\mathrm{BiMnO}_{3}-\mathrm{PbTiO}_{3}$, respectively. ${ }^{18,30} \mathrm{~A}$ similar procedure was followed in this work to optimize the synthesis of the compositions belonging to the ternary system under study. The stoichiometric mixtures of the reactants were mechanically treated for different times depending on the compositions: $24 \mathrm{~h}$ of milling time was required to fully crystallize the perovskite phase for compositions with high amount of $\mathrm{BiFeO}_{3}$, i.e., with $0 \leq x \leq 0.5$, while $18 \mathrm{~h}$ of milling time was enough to completely isolate the perovskite phase for the $\mathrm{BiMnO}_{3}$-rich edge compositions, that is, with $0.5<x \leq 1$. These milling times were rather short as compared to those usually required for mechanosynthesis, and thus negligible contamination resulted. Contamination levels typically found were below 35 and 500 ppm of Co and W, respectively, as measured by inductively coupled plasma (ICP) - elemental analysis (WC grinding media are actually WC-Co cermets).

Figure 2(a) shows the phase evolution with the milling time of the starting mixture corresponding to sample with $x=0.15$, taken by way of example. The two steps mentioned above during the milling process can be clearly observed: reagents are roughly amorphized and particle size is reduced after $18 \mathrm{~h}$ of milling, though diffraction peaks corresponding to the perovskite phase can already be detected, while single-phase perovskite could be fully crystallized after $24 \mathrm{~h}$ of milling, and remains stable with further increase of the milling time. The mechanosynthesized powder consisted of submicron-sized agglomerates of nano-sized crystals, as displayed in the TEM image of Fig. 2(b). The Feret's diameter distribution, also included in the figure, was obtained by measuring more than 150 particles. An average size 
of $35 \mathrm{~nm}$ and standard deviation of $18 \mathrm{~nm}$ resulted. Similar powder morphology and average crystal sizes were achieved in all compositions under study.

Figure 3 shows the XRD patterns of different compositions indicating that the perovskite could successfully be isolated as single phase by mechanosynthesis, either after 18 or $24 \mathrm{~h}$ of milling time, as outlined above. It is evident that symmetries other than pseudo-cubic cannot be identified from these patterns, due to the nanocrystalline nature of the mechanosynthesized powders. In order to increase the crystallinity of the powders to study the phase stability and phase coexistence, thermal treatments at different temperatures were carried out. Figure 4 shows the XRD patterns of the different perovskites after mechanosynthesis and subsequent thermal treatment at $950{ }^{\circ} \mathrm{C}$ for $2 \mathrm{~h}$. In all cases, the powders were successfully crystallized into the perovskite-type structure (no secondary phases were found), in which symmetries lower than pseudo-cubic can be assessed. Phase coexistence is found along the entire line of compositions, in which two compositional ranges may be differentiated.

For compositions close to the $\mathrm{BiFeO}_{3}-\mathrm{PbTiO}_{3}$ end member, i.e., $0 \leq x \leq 0.325$, coexistence of two polymorphs with tetragonal and rhombohedral (or monoclinic) symmetries is clearly observed, the latter being the major phase, in agreement with the MPB of the $\mathrm{BiFeO}_{3}-\mathrm{PbTiO}_{3}$ binary system (see Fig. 4(b) for comparison). ${ }^{17-20}$ It should be noted that it is unfeasible to discriminate between the rhombohedral and monoclinic symmetries from our standard XRD data, for which a Rietveld study would be required, and even then it is not straightforward as illustrated by the contradicting previous reports. With increasing the amount of $\mathrm{BiMnO}_{3}$ the tetragonal phase starts to prevail over the $R 3 c / C c$ one, which is hardly discernible above $x=$ 0.425. Nevertheless, phase coexistence is still present for all compositions up to the $\mathrm{BiMnO}_{3}$ $\mathrm{PbTiO}_{3}$ edge member (see also Fig. 4(b)), wherein the MPB must involve polymorphs with tetragonal and orthorhombic symmetries, according to the MPB described for the binary system. ${ }^{30}$ Although coexisting polymorphic phases are being assumed isostructural with the 
edge binary systems, it must be remarked again that our XRD data do not allow symmetry to be unambiguously ascertained.

The lattice parameters were determined by least-square refinement method from the XRD data for the tetragonal phase, and their evolution with the composition is shown in Fig. 5 (standard deviation is represented as $3 \sigma$ ). The tetragonal $P 4 m m$ space group was used for the calculation. Again, two compositional ranges may be clearly differentiated, i.e., below and above $x=0.5$. The huge tetragonality (ratio of the cell parameters, c/a) exhibited for the MPB $0.7 \mathrm{BiFeO}_{3}-0.3 \mathrm{PbTiO}_{3}$ composition (c/a $\sim 1.18$ ), though still high for compositions close to the end member, decreases significantly with increasing $\mathrm{BiMnO}_{3}$ content and spontaneous strain (c/a-1) becomes 3 times lower (c/a $\sim 1.06)$ for $x=0.5$. At this composition, the ternary system shows roughly the same c/a ratio than $\mathrm{PbTiO}_{3}$. For compositions $x>0.5$, the tetragonality continues decreasing, but at a different rate, reaching a minimum for the $\mathrm{MPB} 0.4 \mathrm{BiMnO}_{3-}$ $0.6 \mathrm{PbTiO}_{3}$ composition (c/a $\sim 1.03$ ). Note that in ferroelectrics perovskites, large tetragonality (spontaneous strain) means large polarization and high $\mathrm{T}_{\mathrm{C}}$, but also high coercitivity which makes polarization switching difficult, needing very-high electric fields. In addition, the processing of high-quality ceramics is highly challenging for such large tetragonalities. A reduction of the c/a ratio in some extent could be even advantageous for optimal processing and better functionality, in particular for MPB systems.

For $\mathrm{PbTiO}_{3}$-based piezoelectric materials, the highest performance occurs at the MPB, in which rhombohedral (or monoclinic) polymorphs coexist with a tetragonal one that exhibits typically c/a $\sim 1.025 .{ }^{33}$ For these materials, c/a ratio typically decreases from $\sim 1.064$ (value for $\mathrm{PbTiO}_{3}$ ) on approaching the MPB, while no significant change takes place in the lattice volume across it, like the cases of $\mathrm{Pb}(\mathrm{Zr}, \mathrm{Ti}) \mathrm{O}_{3}$ or $\mathrm{Pb}\left(\mathrm{Mg}_{1 / 3} \mathrm{Nb}_{2 / 3}\right) \mathrm{O}_{3}-\mathrm{PbTiO}_{3}$ among many others. The solid solution of $\mathrm{BiFeO}_{3}-\mathrm{PbTiO}_{3}$ present a different $\mathrm{MPB}$, and it is perhaps the only ferroelectric perovskite with a polymorphic MPB region that shows increasing c/a ratio 
with decreasing $\mathrm{PbTiO}_{3}$, and also an abrupt change in the lattice volume at the MPB when moving from one polymorph to other. ${ }^{18,22}$ Its tetragonality is perhaps the highest reported in ferroelectric MPB systems. In relation to the ternary system under study, an evolution from this latter type of MPB to the former one seems to happen. Therefore, the slope change in the c/a vs. $x$ curve at composition with $x \sim 0.5$, might indicates this evolution. Experimental and theoretical studies have shown the key role of the hybridization between $(\mathrm{Bi}, \mathrm{Pb})(6 \mathrm{~s}, 6 \mathrm{p})$ and $\mathrm{O}(2 \mathrm{p})$ orbitals for the huge tetragonality of $\mathrm{MPB} \mathrm{BiFeO}_{3}-\mathrm{PbTiO}_{3} \cdot{ }^{34}$ However, tetragonality is strongly coupled to the $B$-cation displacement and weakly coupled to the $A$-cation one, ${ }^{33}$ so the role of the substitution of $\mathrm{Mn}^{3+}$ by $\mathrm{Fe}^{3+}$ in covalency effects should also be considered.

\subsection{Magnetic behavior of nanopowders and crystallized phases}

The strength of the magnetic interactions was investigated by classical ZFC/FC cycles. Figure 6 shows the temperature dependence of the molar magnetic susceptibility (M/H ratio) for the mechanosynthesized perovskites with different compositions. The nanocrystalline powders showed magnetic interactions in all cases, yet large differences were observed at low-temperature with increasing $\mathrm{BiMnO}_{3}$ content. For the $\mathrm{BiFeO}_{3}$-rich compositions, i.e., $x \leq$ 0.425 (Fig. 6(b)), the curves display mainly an overall paramagnetic behavior, yet a manifest irreversibility between the ZFC and FC curves can be observed. This extends up to the maximum measuring temperature, $c a .400 \mathrm{~K}$, and might indicate the presence of magnetic frustration in a system of weakly interacting nanoparticles.

However, upon increasing the amount of $\mathrm{BiMnO}_{3}$ in the mechanosynthesized powders, i.e., $x \geq 0.5$ (Fig. 6(a)), several features can be distinguished. First, the irreversibility of the $\mathrm{ZFC} / \mathrm{FC}$ curves vanishes above a temperature as low as $\sim 15 \mathrm{~K}$ in all cases, indicating a clear paramagnetic behavior and the absence of any, even weak, magnetic order at higher temperatures. Secondly, the susceptibility, and therefore the strength of magnetic interactions 
at $2 \mathrm{~K}$, increases by an order of magnitude between both extremes of the series, due to the increasing content of $\mathrm{Mn}^{3+}$ ions in $B$-sites. And finally, the ZFC curves exhibit a cusp-like feature, along with a divergence of the ZFC and FC curves below $10 \mathrm{~K}$, which is nearly independent on composition, whereas FC ones steadily increases on cooling. These features may be reminiscent of systems undergoing spin glass-like transitions or may well suggest the presence of magnetic frustration in interacting nanocrystalline particles, and the anomaly in the ZFC curves corresponds to the blocking temperature, $\mathrm{T}_{\mathrm{B}} .{ }^{35,36}$ The isothermal hysteresis loops (M-H) recorded at $2 \mathrm{~K}$, and shown in the inset of Fig. 6 for two selected compositions, indicate a weak ferromagnetic contribution with similar coercitivity of $\sim 1 \mathrm{kOe}$, a feature that is rather consistent with a spin-glass-like behavior.

The overall magnetic behavior differs also widely from the $\mathrm{BiFeO}_{3}$-rich to the $\mathrm{BiMnO}_{3}$ rich compositional regions in the thermally treated $\left(950{ }^{\circ} \mathrm{C} / 2 \mathrm{~h}\right.$ followed by quenching) powdered materials. Figure 7 shows the temperature dependence of the molar magnetic susceptibility (M/H ratio) in $\mathrm{ZFC} / \mathrm{FC}$ cycles for various compositions, in which several features are worth noticing. The magnetization behavior of the $0.7 \mathrm{BiFeO}_{3}-0.3 \mathrm{PbTiO}_{3}(x=0)$ composition is given in Fig. 7(a). Note the presence of a magnetic anomaly at about $394 \mathrm{~K}$, below which large divergence between the ZFC and FC curves is observed. $\mathrm{T}_{\mathrm{N}}$ for $R 3 c / C c$ phases around the MPB of the $\mathrm{BiFeO}_{3}-\mathrm{PbTiO}_{3}$ system has been reported to be at $\sim 473 \mathrm{~K}^{23,25}$ The observed anomaly at $394 \mathrm{~K}$ must be associated with the spin-reorientation transition, $\mathrm{T}_{\mathrm{SRO}}$, wherein the ferromagnetic component undergoes a spin flop. ${ }^{26}$ It is remarkable the further divergence of the $\mathrm{ZFC}$ and $\mathrm{FC}$ magnetizations below $\mathrm{T}_{\mathrm{SRO}}$ that indicates a larger net magnetic moment from the spin-canting. This ferromagnetic component, although small, is measurable and can be very useful in the search of room-temperature magnetoelectric effects.

Upon adding small amounts of $\mathrm{BiMnO}_{3}$ in the ternary system, i.e., $x=0.15$ and 0.25 (Figs. 7(b) and 7(c), respectively), the $\mathrm{T}_{\mathrm{SRO}}$ shifts towards lower temperature, at 305 and $222 \mathrm{~K}$, 
respectively. Above the anomaly, irreversibility of the ZFC/FC curves persists and indicates the system still presents the AFM ordering temperature above the measuring range (above $400 \mathrm{~K})$. For the material with $x=0.15$, the gap between $\mathrm{ZFC}$ and $\mathrm{FC}$ curves below the $\mathrm{T}_{\mathrm{SRO}}$ increases, and indicates larger magnetization than that for $x=0$. For the system with $x=0.25$, the $\mathrm{T}_{\mathrm{SRO}}$ shifts below RT and the gap between $\mathrm{ZFC}$ and FC curves decreases and therewith the spin-canted ferromagnetic component. Here, the magnetic phenomenon seems to coexist with the paramagnetic contribution of a new anomaly with ordering temperature close to $2 \mathrm{~K}$.

Both, the AFM ordering and spin-reorientation phenomena observed in the $\mathrm{BiFeO}_{3}$-rich compositions are certainly related with a superexchange pathway that involves nonmagnetic cations of the type $\mathrm{Fe}^{3+}-\mathrm{O}^{2-}-\mathrm{Ti}^{4+}-\mathrm{O}^{2-}-\mathrm{Fe}^{3+}$, wherein addition of $\mathrm{BiMnO}_{3}$ further increases the chemical disorder at the $\mathrm{Fe}^{3+}$ magnetic sublattice. This should lead to competing interactions that results in the lowering of the ordering temperatures, and therefore, the vanishing of the spin-canted ferromagnetic component at RT. Figure 8 shows the isothermal $\mathrm{M}$ vs $\mathrm{H}$ curves recorded at $300 \mathrm{~K}$ for $\mathrm{BiFeO}_{3}$-rich compositions, in which the suppression of the $\mathrm{RT}$ ferromagnetic component with increasing $\mathrm{BiMnO}_{3}$ content is evidenced. In spite of the hysteresis loops still showing some irreversibility for compositions up to $x=0.325$, remnant magnetization is negligible and coercive fields of only few hundred Oe are obtained.

The magnetic behavior changes for $\mathrm{BiMnO}_{3}$-rich compositions, i.e., $x \geq 0.5$, as shown in Figs. 7(d-f). The ZFC/FC curves indicate the absence of proper long-range order, marked by an overall paramagnetic behavior down to very low temperatures. The magnetization curves for the $0.4 \mathrm{BiMnO}_{3}-0.6 \mathrm{PbTiO}_{3}$ composition $(x=1)$, given in Fig. $7(\mathrm{f})$, show a cusp-like feature in ZFC and an almost constant magnetization below $10 \mathrm{~K}$, which is typical of systems undergoing spin glass-like or cluster glass-like transitions, and may well suggest the presence of magnetic frustration with competing short-range $\mathrm{FM}$ or $\mathrm{AFM}$ interactions. $\mathrm{BiMnO}_{3}$ is an orbitally ordered ferromagnetic insulator that is chosen in the ternary system due to its 
tendency to form ferromagnetic couplings below ca. $105 \mathrm{~K}^{37}$ However, in this case, superexchange pathways involving nonmagnetic cations of the type $\mathrm{Mn}^{3+}-\mathrm{O}^{2-}-\mathrm{Ti}^{4+}-\mathrm{O}^{2-}-\mathrm{Mn}^{3+}$, avoid the development of a full long-range magnetic order. It is known that a random orientation of frozen spins can occur when the concentration of magnetic ions is diluted or the magnetic exchange interactions are frustrated. ${ }^{35,36}$

No significant differences were observed at some lower content of $\mathrm{BiMnO}_{3}$, as shown for the $x \geq 0.75$ materials (see Fig. 7(e)), except a decrease of the susceptibility at $2 \mathrm{~K}$ due to the further dilution of the $\mathrm{Mn}^{3+}$ ions. For middle compositions, i.e., $x=0.5$, the magnetization curves seem to indicate a behavior in between those described above, as shown in Fig. 7(d). In this case, two anomalies can be differentiated in the susceptibility curves (inset of Fig. $7(d)$ ), which seem to indicate the coexistence of magnetic orderings, perhaps associated to separate superexchange of $\mathrm{Mn}^{3+}$ and $\mathrm{Fe}^{3+}$ interacting ions. The anomaly at lower temperature, at about $10 \mathrm{~K}$, could be related with the $\mathrm{T}_{\mathrm{B}}$ of the spin-glass state, whereas the anomaly at about $23 \mathrm{~K}$, for which a divergence of the curves is obtained, could be the $\mathrm{T}_{\mathrm{N}}$ of the AFM ordering associated with the magnetic Fe sublattice. It should be noted, that tetragonal is the predominant phase in this compositional range, according to XRD data (see Fig. 4), so the magnetic response should be associated with this phase. $\mathrm{T}_{\mathrm{N}}$ was reported to be at $\sim 220 \mathrm{~K}$ for the $P 4 m m$ phase at the MPB of the $\mathrm{BiFeO}_{3}-\mathrm{PbTiO}_{3}$ system. ${ }^{24}$ Results therefore indicate the frustration of the magnetic interactions and a spin- or cluster-glass-type behavior for the tetragonal phase in the $\mathrm{BiMnO}_{3}$-rich compositions.

At high temperatures $(150-300 \mathrm{~K}$, well above the magnetic ordering), the linear increase of the inverse susceptibility with increasing temperature is related to the Curie-Weiss paramagnetic behavior $\left(\chi=\frac{C}{(T-\theta)}\right)$, where $C$ is Curie constant and $\theta$ is Weiss constant, from which the overall effective moment can be extracted $\left(\mu_{\text {eff }}=(8 C)^{1 / 2}\right)$. An effective moment per 
nominal Mn content $\mu_{\mathrm{eff}} / \mathrm{Mn}$ of $4.67 \mu_{\mathrm{B}}\left(\mu_{\mathrm{B}}=\right.$ Bohr magneton) was obtained for the $0.4 \mathrm{BiMnO}_{3}-0.6 \mathrm{PbTiO}_{3}$ composition. This value is less than that expected for a full $\mathrm{Mn}^{3+}$ contribution $\left[\mu\left(\mathrm{Mn}^{3+}\right)=4.90 \mu_{\mathrm{B}}\right]$, and suggests the presence of a mixed valence $3+/ 4+$ for $\mathrm{Mn}$ atoms at the magnetic sublattice $\left[\mu\left(\mathrm{Mn}^{4+}\right)=3.87 \mu_{\mathrm{B}}\right]$. Upon adding $\mathrm{BiFeO}_{3}$, an effective moment $\mu_{\mathrm{eff}} /(\mathrm{Mn}+\mathrm{Fe})$ of $4.75 \mu_{\mathrm{B}}$, normalized to the $\mathrm{Mn}+\mathrm{Fe}$ content, was calculated for the composition with $x=0.75$. This value largely differs to that expected by considering the corresponding amount of $\mathrm{Fe}^{3+}\left[\mu\left(\mathrm{Fe}^{3+}\right)=5.92 \mu_{\mathrm{B}}\right]$, for which $\mu_{\mathrm{eff}} /(\mathrm{Mn}+\mathrm{Fe})=5.25 \mu_{\mathrm{B}}$ would be anticipated by considering only $\mathrm{Mn}^{3+}$ and $\mathrm{Fe}^{3+}$, and suggests mixed-valence states for both $\mathrm{Mn}(3+/ 4+)$ and $\mathrm{Fe}(3+/ 2+)$ cations at $B$-site. This would be disadvantageous as it could enable electron hopping-type conductivity that prevents making use of the ferroelectric properties.

XPS analysis was carried out to confirm the oxidation states of Fe and Mn. Figure 9(a) shows the narrow scan XPS spectra of the Fe $2 p$ line for $0.7 \mathrm{BiFeO}_{3}-0.3 \mathrm{PbTiO}_{3}(x=0)$ and that for composition with $x=0.75$, for comparison. The Fe $2 p$ orbital is divided into Fe $2 p_{3 / 2}$ at $\sim 710 \mathrm{eV}$ and $\mathrm{Fe} 2 \mathrm{p}_{1 / 2}$ at $\sim 723.5 \mathrm{eV}$, and a satellite of $\mathrm{Fe} 2 \mathrm{p}_{3 / 2}$ is also observed in-between. ${ }^{38}$ The sub peaks can be de-convoluted into two peaks in both samples, which are associated to the presence of $\mathrm{Fe}^{3+}$ and $\mathrm{Fe}^{2+}$ attending to the binding energies. The peaks splitting are hardly observed for the $0.7 \mathrm{BiFeO}_{3}-0.3 \mathrm{PbTiO}_{3}$ material, for which peaks corresponding to $\mathrm{Fe}^{3+}$ dominate the spectrum, yet small peaks associated to the presence of $\mathrm{Fe}^{2+}$ are necessary for successful fitting. The presence of some $\mathrm{Fe}^{2+}$ in the binary system is not unexpected, and indeed might be the origin of relaxations reported in the dielectric properties. ${ }^{28}$ Results are in a good agreement with previous reports in thin-film and nanoparticles. ${ }^{39,40}$ A clear XPS signal associated with $\mathrm{Fe}^{2+}$ is observed for the sample with $x=0.75$, for which the presence of a mixture of $\mathrm{Fe}^{3+}$ and $\mathrm{Fe}^{2+}$ oxidation states can be stated. A large $\mathrm{Fe}^{2+} / \mathrm{Fe}^{3+}$ ratio of 0.57 was obtained from the relative area under the peaks obtained from the fitting. 
On the other hand, similar analysis was performed using the narrow scan XPS spectra of the $\mathrm{Mn} 2 \mathrm{p}$ line for the $0.4 \mathrm{BiMnO}_{3}-0.6 \mathrm{PbTiO}_{3}(x=1)$ and the composition with $x=0.75$, as shown in Fig. 9(b). This orbital also contains doublet component which can be assigned to Mn 2 $\mathrm{p}_{3 / 2}$ and $\mathrm{Mn} 2 \mathrm{p}_{1 / 2}$ lines at $\sim 642 \mathrm{eV}$ and $\sim 653 \mathrm{eV}$, respectively, which could also be deconvoluted into two peaks each. ${ }^{41,42}$ In this case, the fits also take into account the peak for $\mathrm{Pb} 4 \mathrm{p}_{3 / 2}$ at $\sim 645 \mathrm{eV}$. Both the binding energy values and energy difference between the two peaks for each orbital indicate the presence of $\mathrm{Mn}^{4+}$ and $\mathrm{Mn}^{3+}$ oxidation states in the samples. The $\mathrm{Mn}^{4+} / \mathrm{Mn}^{3+}$ ratio was found to be 0.26 for the binary system, e.g., in a good agreement with previous reports in $\mathrm{BiMnO}_{3},{ }^{9}$ which might be the reason behind the shift in the onset of conductivity to very low temperatures. ${ }^{31}$ The ratio increases slightly up to 0.31 for the sample with $x=0.75$. Results demonstrate the presence of mixed-valence states for both Fe and $\mathrm{Mn}$ cations, which increases and compensates each other in the ternary system.

\subsection{Microstructural and dielectric characterization of ceramic materials}

High-density materials are a requirement for the proper study of the dielectric properties and applications. Conventional sintering methods were unable to provide dense materials of the ternary system under study, and secondary phases appear due to the poor stability of these perovskites derived from $\mathrm{BiMnO}_{3}$ and $\mathrm{BiFeO}_{3}$ phases during sintering at high temperatures. ${ }^{43}$

Nanopowders obtained by mechanosynthesis were used to prepare high-quality and singlephase ceramics of the whole ternary system by hot-pressing at moderate temperatures. This allowed high densifications (above $97 \%$ of the theoretical density) to be achieved for all compositions, with grain sizes in the submicron range. Figure 10(a) shows a representative SEM micrograph of the ceramic with $x=0.25$ prepared at $950{ }^{\circ} \mathrm{C}$. This material showed full densification (above 99\%), wherein porosity or traces of secondary phases were not detected. The amplification of this image (see Fig. 10(b)) allowed the observation of twinning planes 
on the grain surface. This topographic feature is caused during surface polishing and etching, and reflects typical ferroelastic domain configuration, i.e., non- $180^{\circ}$ domain walls. ${ }^{44}$ It is not possible to accurately determine the nature of these ferroelastic domains from this image, that is, whether they correspond to $\{110\}$ planes of the tetragonal phase (i.e., for $90^{\circ}$ domains) or to those for the rhombohedral one (i.e., $\{110\}$ planes for $109^{\circ}$ and $\{001\}$ for $71^{\circ}$ domains). ${ }^{45}$ The tendency to develop a herringbone-like configuration, as the one shown in the image, is typical of ferroelectric perovskites regardless the crystallographic phase.

Tailored microstructures with similar features were obtained for all compositions at the $\mathrm{BiFeO}_{3}$-rich region, that is, up to $x=0.425$, making these materials very suitable for the study of the ferroelectric properties. Figure 11(a) shows the temperature dependence of the real $\left(\mathrm{K}^{\prime}\right)$ and the imaginary $\left(\mathrm{K}^{\prime \prime}\right)$ components of the dielectric permittivity at several frequencies during heating for the ceramic with $x=0.25$, taken by way of example. The anomaly associated with the transition from the ferroelectric to the paraelectric phase can be observed in $\mathrm{K}^{\prime}$ curves at $\mathrm{T}_{\mathrm{C}}=850 \mathrm{~K}$ on heating. The presence of low-frequency dispersion at high temperature makes difficult determining Tc but for highest frequencies. Non-negligible conductivity is clearly indicated by the temperature dependence of $\mathrm{K}^{\prime \prime}$, as shown in the inset of the figure, in which the ferroelectric transition cannot be detected. These features indicate the response to be dominated by electrical conduction in this temperature range.

A step-like increase in $\mathrm{K}^{\prime}$ at moderate temperatures and close to RT (around 300 - $500 \mathrm{~K}$ ), whose height decreases and the position shifts to high temperatures with frequency, is also present. This seems to be a Maxwell-Wagner type relaxation associated with the existence of significant but inhomogeneous electrical conduction in the material. This effect accounts for charge accumulation at interfaces, which may be originated in ceramics from various sources, e.g., sample/electrode interfaces, grain boundaries, or even twin boundaries. ${ }^{46}$ Indeed, this effect has been demonstrated key for high dielectric permittivity in numerous materials. ${ }^{47}$ 
Below this relaxation, dispersion in $\mathrm{K}^{\prime}$ is negligible, so it can be considered as the onset of electronic conductivity. This is a main issue in the research on multiferroic perovskite oxides, which makes the characterization of their ferroelectric properties difficult and, for several compounds, even impossible to state the ferroelectric nature. Conductivity in the ternary system under study seems to be associated with electron hopping linked to the presence of cations with mixed-valence states (e.g., $\mathrm{Fe}^{3+} / \mathrm{Fe}^{2+}$ or $\left.\mathrm{Mn}^{3+} / \mathrm{Mn}^{4+}\right)$.

Maxwell-Wagner effects were found in $\mathrm{BiFeO}_{3}-\mathrm{PbTiO}_{3}$ compositions, although takes place at higher temperatures $(500-700 \mathrm{~K}) .{ }^{28}$ The onset of conductivity is then decreased by the addition of Mn, and occurs below RT for compositions above $x=0.25$. This result was expected considering the onset of conductivity in $\mathrm{BiMnO}_{3}$ ceramics, located at very low temperatures, $c a .80-100 \mathrm{~K} .{ }^{9}$ The study of the dielectric properties was then focused on the compositions at the $\mathrm{BiFeO}_{3}$-rich region (up to $x=0.425$ ), for which conductivity is not an issue to distinguish the anomaly associated with the ferroelectric transition.

Figures $11(\mathrm{~b}, \mathrm{c})$ show the temperature dependence of $\mathrm{K}^{\prime}$ and dielectric looses, $\tan \delta$ (ratio $\mathrm{K}^{\prime \prime} / \mathrm{K}^{\prime}$ ), during a thermal heating/cooling cycle, for several compositions. Measurements at the highest frequency $(1 \mathrm{MHz})$ are given to minimize the extrinsic conduction contributions. Dielectric anomalies typically of first-order ferroelectric transitions are found in all cases, at temperatures that decrease with increasing $\mathrm{BiMnO}_{3}$ content. The linear dependence of the $\mathrm{Tc}$ with composition in both heating and cooling runs is shown in the inset of Fig. 11(b). The substitution of $\mathrm{Mn}$ by $\mathrm{Fe}$ in $B$-sites reduces the tetragonality, i.e., the c/a ratio (see Fig. 5), and hence the lattice distortion, which results in the decrease of Tc.

The significant thermal hysteresis at the ferroelectric transition, with a difference in $T_{C}$ between heating and cooling runs $\left(\Delta \mathrm{T}_{\mathrm{C}}\right)$ of $\sim 25 \mathrm{~K}$, is nearly independent on composition. This was already reported for the $\mathrm{BiFeO}_{3}-\mathrm{PbTiO}_{3}$ binary system, for which an anomalous large $\Delta \mathrm{T}_{\mathrm{C}}$ value was found at the MPB. ${ }^{28}$ The compositions under study show similar MPB 
features, in which phase coexistence between $P 4 m m$ and $R 3 c / C c$ polymorphs takes place. The thermal hysteresis is most likely the consequence of a different sequence of polymorphic transitions on heating and cooling, due to the large difference in strains between these two polymorphs, ${ }^{22}$ which is obviously affected by the evolving ceramic stresses. This sequence seems to be likely from the tetragonal phase on heating and to the $R 3 c / C c$ one on cooling, as indicated by XRD before and after the measurements. It is remarkable the evolution of the maximum in $\mathrm{K}^{\prime}$ with composition, which indicates a significant reduction of the polarizability with increasing Mn content. Nevertheless, the actual permittivity, free of conduction artifacts, can only be assessed below the onset of conductivity, which was set well below RT with increasing $\mathrm{BiMnO}_{3}$ content. This is also indicated in the tan $\delta$ curves, as shown in Fig. 11(c).

\section{$4 \quad$ Summary and conclusions}

This work shows the existence of multiferroic compositions belonging to the ternary system $\mathrm{BiFeO}_{3}-\mathrm{BiMnO}_{3}-\mathrm{PbTiO}_{3}$ that are liable to show RT magnetoelectricity. Mechanosynthesis, that is: the synthesis by mechanochemical route was demonstrated optimal for the preparation of nanocrystalline powders with perovskite-type structure by ball milling in a planetary mill. Nanopowders were also successfully used to prepare high-density ceramics of the whole ternary system by hot-pressing. Multiferroicity was indicated for a series of ceramic materials that show coexistence of at least two different polymorphs depending on composition, and are thus at the MPB (actually a line of them). In these materials, the nuclear (polar) and magnetic structures are correlated with the crystal symmetry and therefore changes through the MPB can be anticipated. Indeed MPBs are found along the entire line of compositions, i.e., from $0.7 \mathrm{BiFeO}_{3}-0.3 \mathrm{PbTiO}_{3}$ to $0.4 \mathrm{BiMnO}_{3}-0.6 \mathrm{PbTiO}_{3}$, in which two compositional ranges are differentiated according to their crystal and ferroic features. 
For the $\mathrm{BiFeO}_{3}$-rich compositions, coexistence of polymorphs with $\mathrm{P} 4 \mathrm{~mm}$ and $\mathrm{R} 3 \mathrm{c} / \mathrm{Cc}$ symmetries is observed with huge tetragonality. Tetragonal distortion decreases significantly when approaching $x=0.5$, for which the system shows roughly the same c/a ratio than model $\mathrm{PbTiO}_{3}$. In this compositional range, the magnetic structure exhibits AFM ordering and $\mathrm{T}_{\mathrm{N}}$ above $400 \mathrm{~K}$, and what it is more relevant, a spin-reorientation transition between two AFM states, below which a ferromagnetic component appears by spin-canting. With increasing $\mathrm{BiMnO}_{3}$-content, this transition shifts below $\mathrm{RT}$ and therewith the ferromagnetic component vanishes at RT. The dielectric characterization indicates the ferroelectric transition takes place at temperatures that linearly decrease in the 750 - $950 \mathrm{~K}$ range with increasing $\mathrm{BiMnO}_{3}$.

For the $\mathrm{BiMnO}_{3}$-rich compositions, crystallized powders show low tetragonality with c/a ratio similar to those of many MPB ferroelectrics. In this compositional range, the magnetic behavior considerably changes, and spin glass-like or cluster glass-like behavior was found with $\mathrm{T}_{\mathrm{B}}$ of $\sim 10 \mathrm{~K}$, nearly independent on composition, suggesting the presence of magnetic frustration with competing short-range interactions. The dielectric characterization in this case was nonetheless difficult, in spite of the tailored microstructure, due to the exceptionally high-conductivity even at low temperatures, associated with electron-hopping, due to the presence of mixed valence states of both the Fe and Mn cations.

\section{Acknowledgments}

This work has been founded by the Spanish MINECO (MAT2011-23709). C.M.F-P and H.A. thanks financial support by MINECO (BES 2012-053017) and Ramón y Cajal Programme, respectively. Collaboration between ICMM and ISCR was framed within the COST Action MP0904 SIMUFER. Technical supports by Ms. I. Martínez and Ms. M. M. Antón, both at ICMM-CSIC, are also acknowledged. 


\section{References}

1 J. F. Scott, J. Mater. Chem., 2012, 22, 4567.

2 W. Eerenstein, N. D. Mathur and J. F. Scott, Nature, 2006, 442, 759.

3 J. F. Scott, NPG Asia Mater., 2013, 5, e72.

4 R. Ramesh, Nature, 2009, 461, 1218.

5 J. A. McLeod, Z. V. Pchelkina, L. D. Finkelstein, E. Z. Kurmaev, R. G. Wilks, A. Moewes, I. V. Solovyev, A. A. Belik and E. Takayama-Muromachi, Phys. Rev. B, 2010, 81, 144103.

6 A. A. Belik, J. Solid State Chem., 2012, 195, 32.

7 G. Catalan and J. F. Scott, Adv. Mater., 2009, 21, 2463.

8 P. Baettig, R. Seshadri and N. A. Spaldin, J. Am. Chem. Soc., 2007, 129, 9854.

9 A. Castro, C. Correas, O. Peña, A. R. Landa-Cánovas, M. Algueró, H. Amorín, M. Dollé, E.Vila and T. Hungría, J. Mater. Chem., 2012, 22, 9928.

10 A. A. Belik, K. Kodama, N. Igawa, S. Shamoto, K. Kosuda and E. TakayamaMuromachi, J. Am. Chem. Soc., 2010, 132, 8137.

11 A. Castro, E. Vila, R. Jimenez, J. Hernandez-Velasco, T. Hungría and M. Algueró, Chem. Mater., 2010, 22, 541.

12 A. A. Belik, A. M. Abakumov, A. A. Tsirlin, J. Hadermann, J. Kim, G. V. Tendeloo and E.Takayama-Muromachi, Chem. Mater., 2011, 23, 4505.

13 V. F. Freitas, O. A. Protzek, L. A. Montoro, A. M. Gonçalves, D. Garcia, J. A. Eiras, R. Guo, A. S. Bhalla, L. F. Cotica and I. A. Santos, J. Mater. Chem. C, 2014, 2, 364.

14 A. Perejón, P. E. Sánchez-Jiménez, L. A. Pérez-Maqueda, J. M. Criado, J. Romero de Paz, R. Sáez-Puche, N. Masó and A. R. West, J. Mater. Chem. C, 2014, 2, 8398.

15 D. Damjanovic, IEEE Trans. Ultrason. Ferroelectr. Freq. Control, 2009, 56, 1574.

16 O. Dieguez and J. Iñiguez, Phys. Rev. Lett., 2011, 107, 057601. 
17 T. P. Comyn, T. Stevenson, M. Al-Jawad, S. L. Turner, R. I. Smith, W. G. Marshall, A. J. Bell and R. Cywinski, Appl. Phys. Lett., 2008, 93, 232901.

18 C. Correas, T. Hungria and A. Castro, J. Mater. Chem., 2011, 21, 3125-3132.

19 V. Kothai, R. P. Babu and R. Ranjan, J. Appl. Phys., 2013, 114, 114102.

20 V. Kothai, A. Senyshyn and R. Ranjan, J. Appl. Phys., 2013, 114, 084102.

21 D. I. Woodward, I. M. Reaney, R. E. Eitel and C. A. Randall, J. Appl. Phys., 2003, 94, 3313.

22 S. Bhattacharje and D. Pandey, J. Appl. Phys., 2010, 107, 124112.

23 W. M. Zhu, H. Y. Guo and Z. G. Ye, Phys. Rev. B, 2008, 78, 014401.

24 T. P. Comyn, T. Stevenson, M. Al-Jawad, G. André, A. J. Bell and R. Cywinski, J. Magn. Magn. Mater., 2011, 323, 2533.

25 S. Bhattacharjee, A. Senyshyn, P. S. R. Krishna, H. Fuess and D. Pandey, Appl. Phys. Lett., 2010, 97, 262506.

26 S. Bhattacharjee, A. Senyshyn, H. Fuess and D. Pandey, Phys. Rev. B, 2013, 87, 054417.

27 H. Amorín, C. Correas, P. Ramos, T. Hungría, A. Castro and M Algueró, Appl. Phys. Lett., 2012, 101, 172908.

28 H. Amorín, C. Correas, C. M. Fernández-Posada, O. Peña, A. Castro and M. Algueró, J. Appl. Phys., 2014, 115, 104104.

29 D. I. Woodward and I. M. Reaney, J. Phys. Condens. Matter., 2004, 16, 8823.

30 T. Hungría, C. Correas, F. Houdellier, O. Peña, E. Vila and A. Castro, Chem. Eur. J., 2012, 18, 9075 .

31 H. Amorín, R. Jiménez, E.Vila, M. Dollé, A. Castro and M. Algueró, Phase Transitions, $2013,86,681$.

32 J. Laugier, B. Bochu, in CELREF V3 Program, Ecole Nationale Supérieure de Physique de Grenoble, France, 2003. 
33 T. Qi, I. Grinberg and A. M. Rappe, Phys. Rev. B, 2010, 82, 134113.

34 M. Yashima, K. Omoto, J. Chen, H. Kato and X. Xing, Chem. Mater., 2011, 23, 3135.

35 M. Knobel, W. C. Nunes, L. M. Socolovsky, E. De Biasi, J. M. Vargas and J. C.

Denardin, J. Nanosci. Nanotechnol., 2008, 8, 2836.

36 M. Bandyopadhyay and S.Dattagupta, Phys. Rev. B, 2006, 74, 214410.

37 T. Atou, H. Chiba, K. Ohoyama, Y. Yamaguchi and Y. Syono, J. Solid State Chem., 1999, 145, 639.

38 T. Yamashita and P. Hayes, Appl. Surf. Sci., 2008, 254, 2441.

39 L. Hai-Min, G. Hong-Li, L. Xue-Dong, L. Guo, X. Ding-Quan and Z. Jian-Guo, J. Inorg. Mater., 2011, 26, 1053.

40 A. Tamilselvan, S. Balakumar, M. Sakar, C. Nayek, P. Murugavel and K. S. Kumar, Dalton Trans., 2014, 43, 5731.

41 B. Y. Zhao, Y. Sun, Y. Yue, X. Hu and M. Xia, Electrochim. Acta, 2014, 130, 66.

42 G. Dong, G. Tan, Y. Luo, W. Liu, A. Xia and H. Ren, Appl. Surf. Sci., 2014, 305, 55.

43 T. Rojac, A. Bencan, B. Malic, G. Tutuncu, J. L. Jones, J. E. Daniels and D.

Damjanovic, J. Am. Ceram. Soc., 2014, 97, 1993.

44 A. Tagantsev, L. E. Cross and J. Fousek, in Domains in ferroic crystals and thin films, Springer, 2010.

45 J. Ricote, R. W. Whatmore and D. J. Barber, J. Phys.: Condens. Matter, 2000, 12, 323.

46 C. Elissalde and J. Ravez, J. Mater. Chem., 2001, 11, 1957.

47 P. Lunkenheimer, R. Fichtl, S. G. Ebbinghaus and A. Loidl, Phys. Rev. B, 2004, 70, 172102. 


\section{Figure captions}

Fig. 1 Schematic phase diagram of the $\mathrm{BiFeO}_{3}-\mathrm{BiMnO}_{3}-\mathrm{PbTiO}_{3}$ ternary system, and selected compositions indicated with closed circles.

Fig. 2 (a) Evolution with the milling time of the initial mixture corresponding to composition with $x=0.15$ (P: Perovskite), and (b) TEM image of the mechanosynthesized powder along with the particle size distribution.

Fig. 3 XRD patterns of the powders obtained by mechanosynthesis after 18 / $24 \mathrm{~h}$ of milling time. Numbers correspond to the compositions identified in Fig. 1.

Fig. 4 (a) XRD patterns of powders after mechanosynthesis and thermal treatment at $950{ }^{\circ} \mathrm{C}$ / 2 h. Numbers correspond to the compositions identified in Fig. 1. (b) Evidence of phase coexistence for all compositions; BM-PT $\left(0.4 \mathrm{BiMnO}_{3}-0.6 \mathrm{PbTiO}_{3}\right)$ and $\mathrm{BF}-\mathrm{PT}\left(0.7 \mathrm{BiFeO}_{3}-\right.$ $0.3 \mathrm{PbTiO}_{3}$ ). $\mathrm{T}$ and $\mathrm{M}$ stand for the tetragonal and monoclinic symmetries, respectively.

Fig. 5 Evolution of the tetragonal lattice parameters $\left(\mathrm{a}_{\mathrm{T}}, \mathrm{c}_{\mathrm{T}}\right)$ and tetragonality $(\mathrm{c} / \mathrm{a})$ of the ternary system $x\left(0.4 \mathrm{BiMnO}_{3}-0.6 \mathrm{PbTiO}_{3}\right)-(1-x)\left(0.7 \mathrm{BiFeO}_{3}-0.3 \mathrm{PbTiO}_{3}\right)$. Standard deviation is represented as $3 \sigma$. Tetragonality value for $\mathrm{PbTiO}_{3}$ is indicated.

Fig. 6 ZFC (closed symbols) and FC (open symbols) magnetization curves of $x\left(0.4 \mathrm{BiMnO}_{3}-\right.$ $\left.0.6 \mathrm{PbTiO}_{3}\right)-(1-x)\left(0.7 \mathrm{BiFeO}_{3}-0.3 \mathrm{PbTiO}_{3}\right)$ phases after mechanosynthesis. Inset: Isothermal magnetization vs magnetic field recorded at $2 \mathrm{~K}$ for two compositions, $x=0.5$ and 0.75 .

Fig. 7 ZFC (closed symbols) and FC (open symbols) magnetization curves of $x\left(0.4 \mathrm{BiMnO}_{3}\right.$ $\left.0.6 \mathrm{PbTiO}_{3}\right)-(1-x)\left(0.7 \mathrm{BiFeO}_{3}-0.3 \mathrm{PbTiO}_{3}\right)$ phases crystallized with thermal treatments at 950 ${ }^{\circ} \mathrm{C} / 2$ h, with $x$ equal to (a) 0 , (b) 0.15 , (c) 0.25 , (d) 0.5 , (e) 0.75 , (f) 1 . 
Fig. 8 Isothermal magnetization vs magnetic field loops recorded at $300 \mathrm{~K}$ of selected compositions with $x=0,0.25$ and 0.5 , after mechanosynthesis and thermal treatment.

Fig. 9 Narrow scan XPS spectra corresponding to (a) $\mathrm{Fe} 2 \mathrm{p}$ and (b) $\mathrm{Mn} 2 \mathrm{p}$, for $0.7 \mathrm{BiFeO}_{3}-$ $0.3 \mathrm{PbTiO}_{3}(x=0), 0.4 \mathrm{BiMnO}_{3}-0.6 \mathrm{PbTiO}_{3}(x=1)$ and compositions with $x=0.75$.

Fig. 10 SEM micrographs of the ceramic with $x=0.25$ obtained by hot-pressing at $950{ }^{\circ} \mathrm{C}$, and (b) amplification of the image to show twinning planes on the grain surface typically of ferroelastic domains.

Fig. 11 (a) Temperature dependence of the real $\left(K^{\prime}\right)$ and the imaginary $\left(K^{\prime \prime}\right.$, inset) permittivity for a ceramic with $x=0.25$. Arrows indicate increasing frequency. (b) $\mathrm{K}^{\prime}$ and (c) looses as a function of temperature during a thermal cycle for ceramics $x\left(0.4 \mathrm{BiMnO}_{3}-0.6 \mathrm{PbTiO}_{3}\right)-(1-x)$ $\left(0.7 \mathrm{BiFeO}_{3}-0.3 \mathrm{PbTiO}_{3}\right)$. (Inset) Evolution of Curie temperature $\mathrm{T}_{\mathrm{C}}$ with composition. 
Figure 1

$x\left(0.4 \mathrm{BiMnO}_{3}-0.6 \mathrm{PbTiO}_{3}\right)-(1-x)\left(0.7 \mathrm{BiFeO}_{3}-0.3 \mathrm{PbTiO}_{3}\right)$

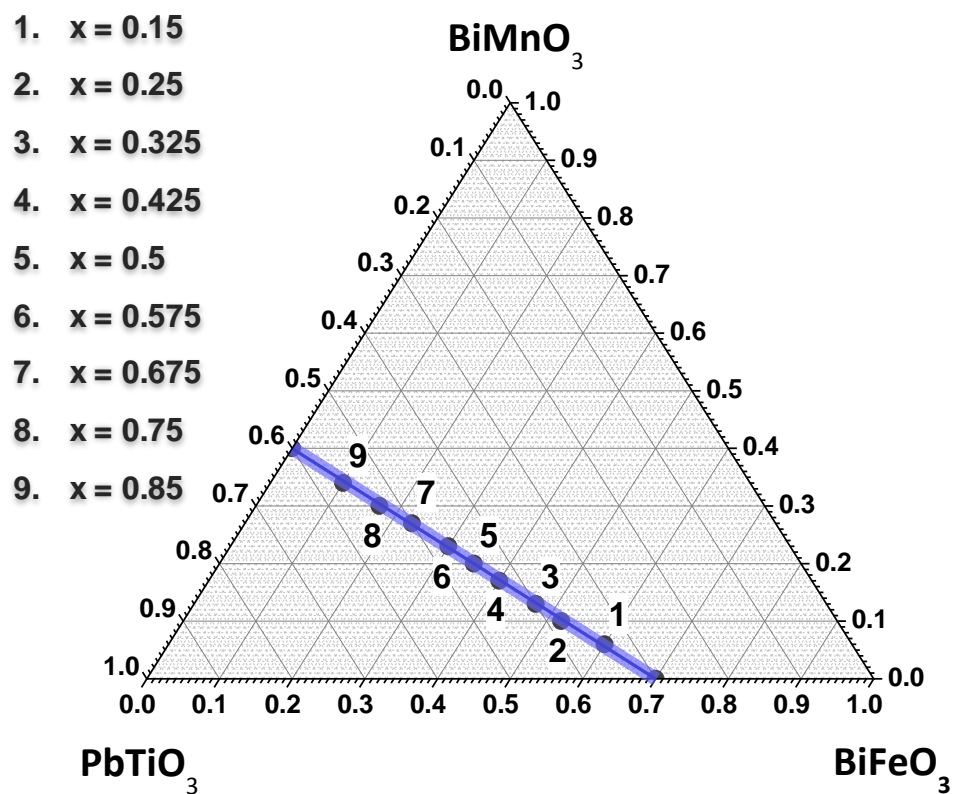


Figure 2
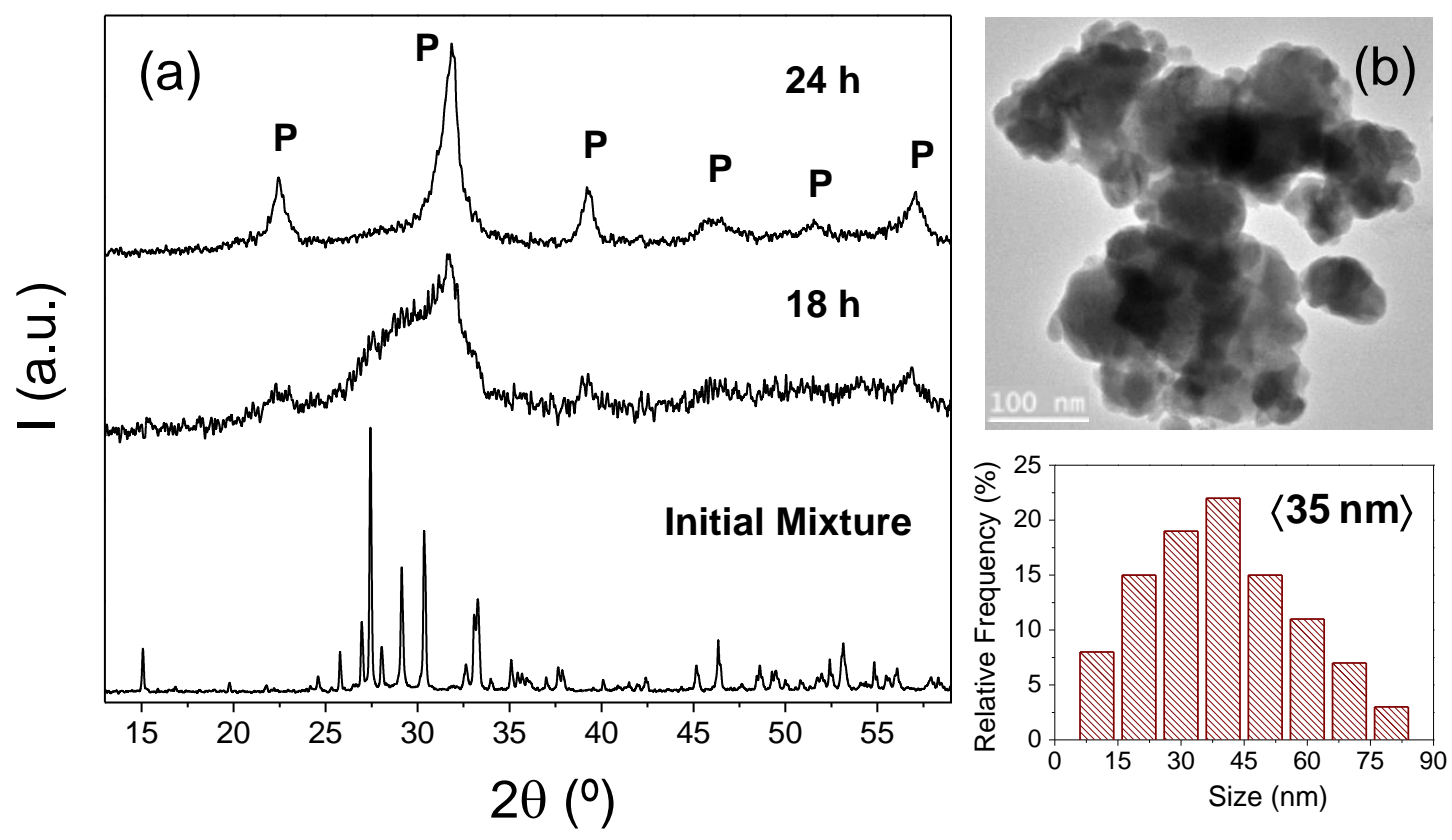
Figure 3

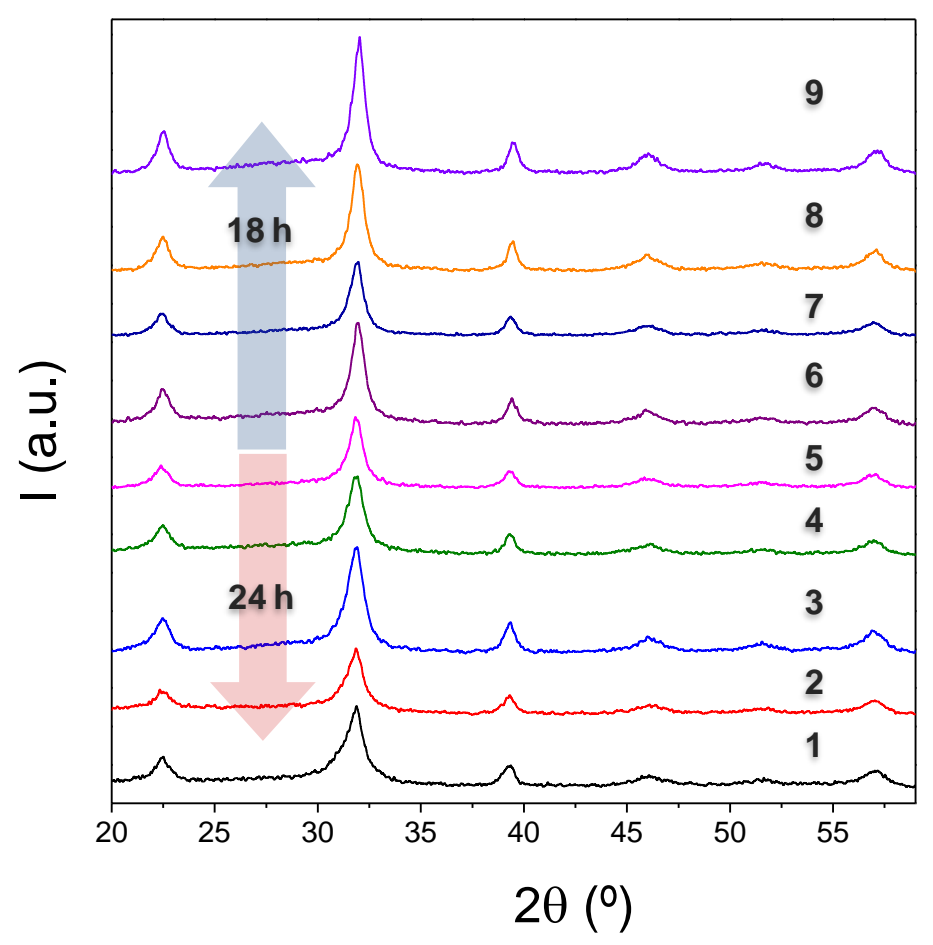


Figure 4

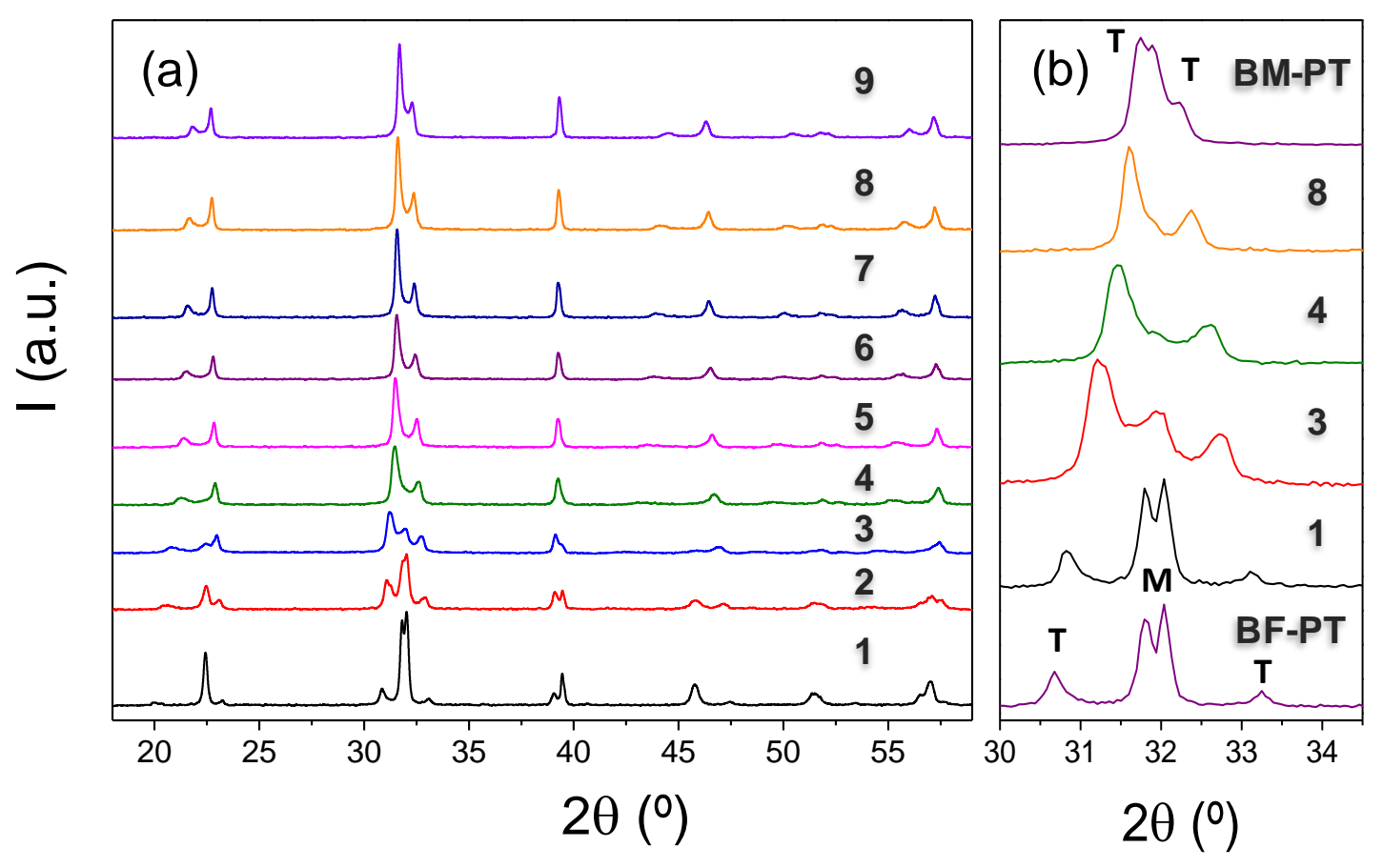


Figure 5

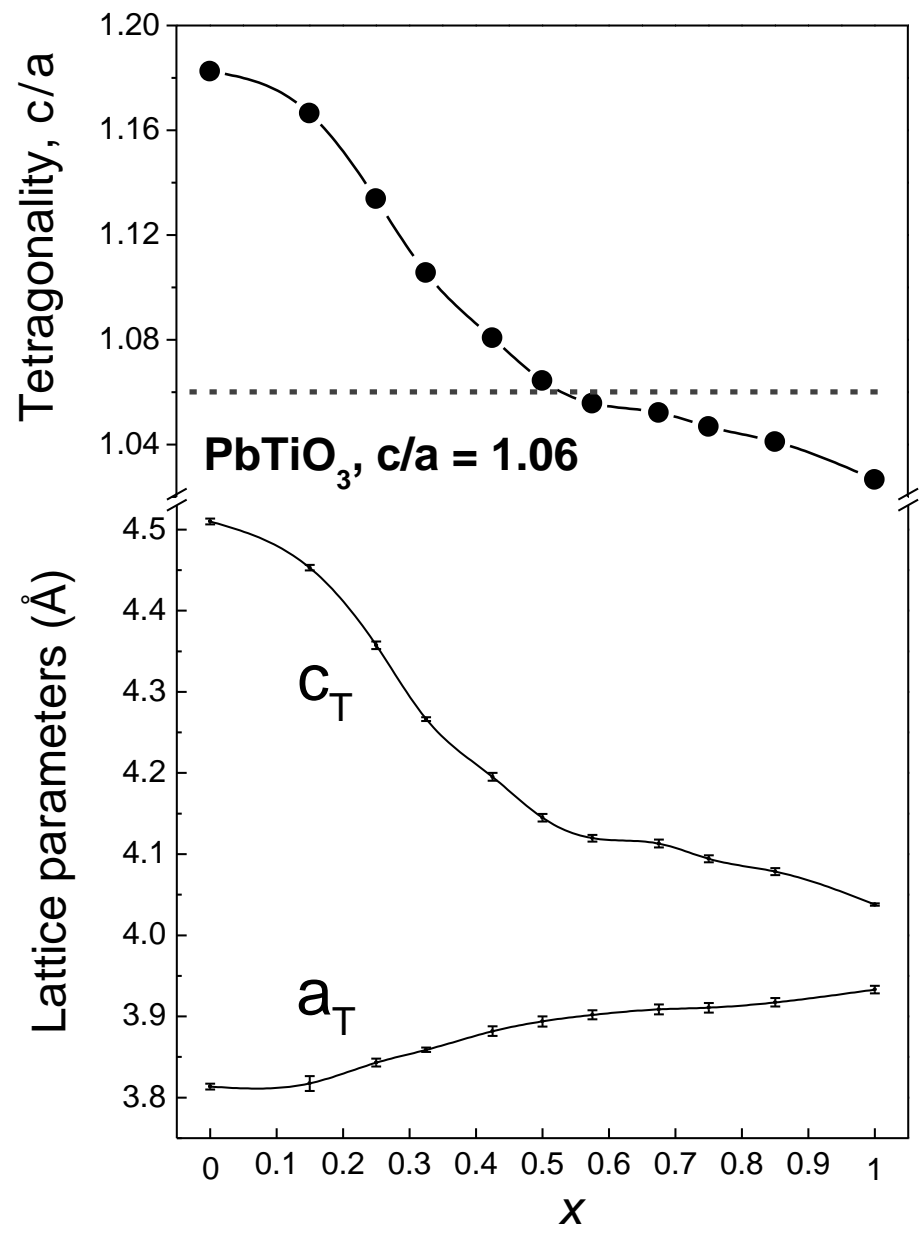


Figure 6

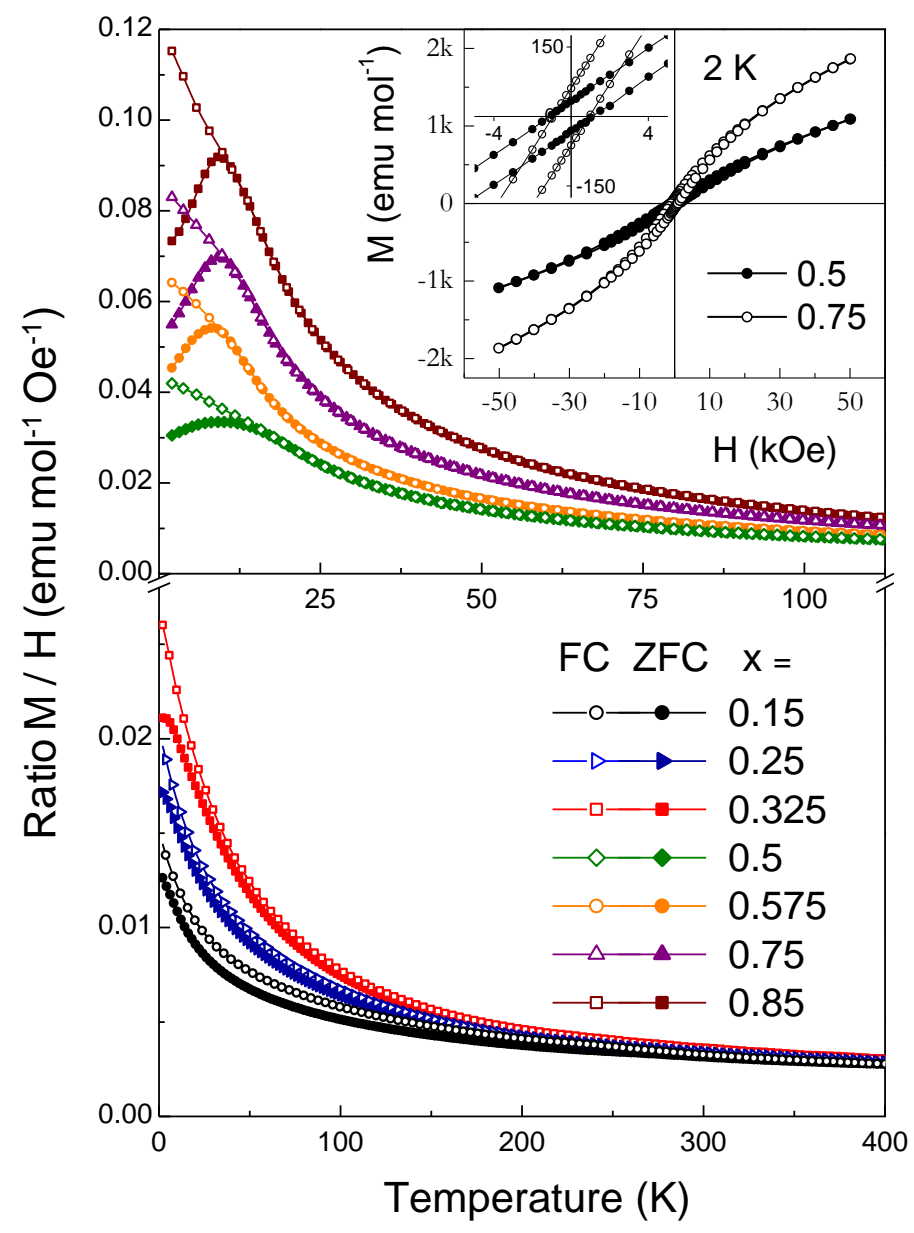


Figure 7
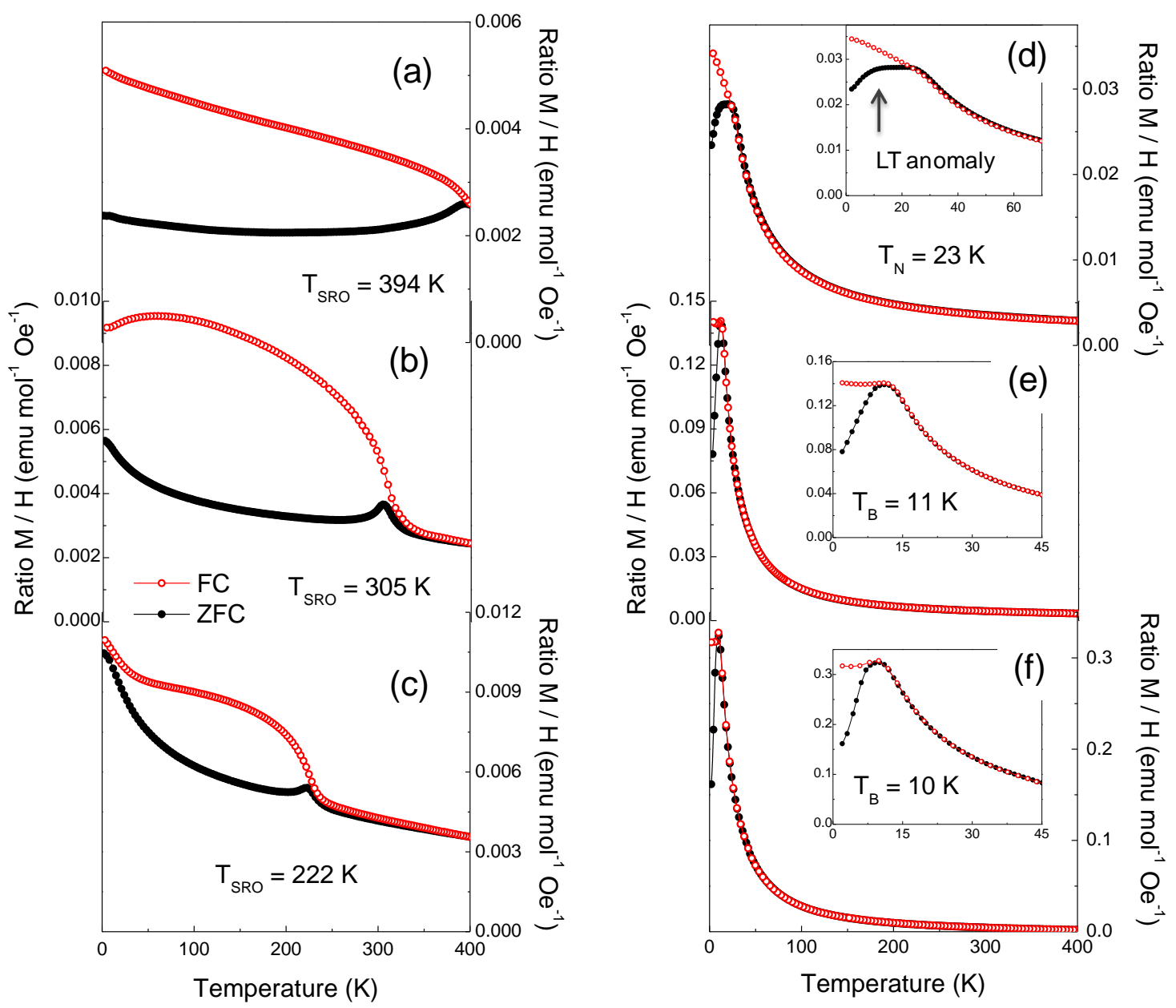
Figure 8

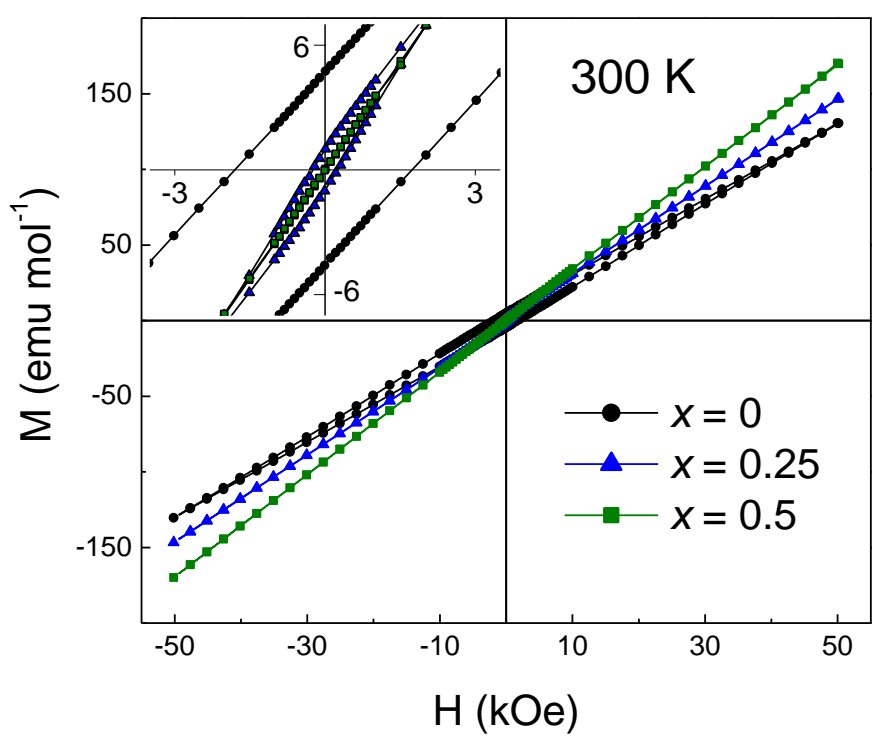


Figure 9
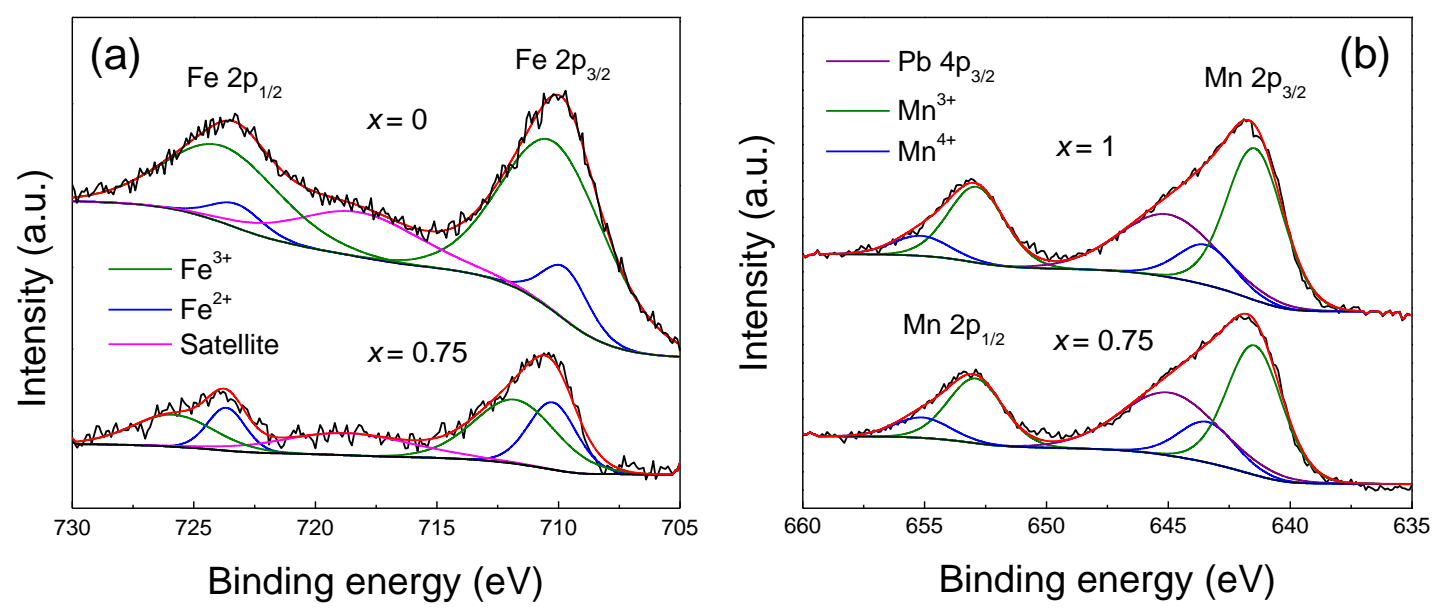
Figure 10

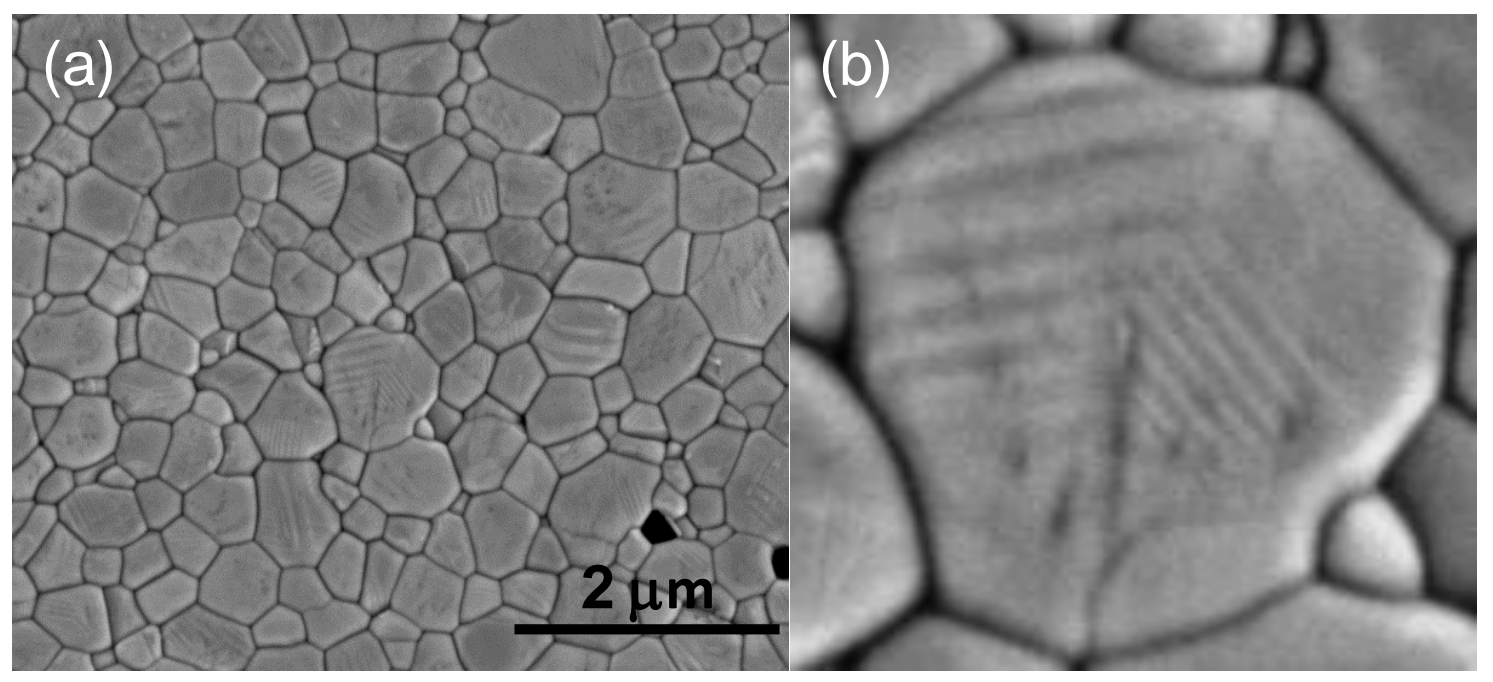


Figure 11
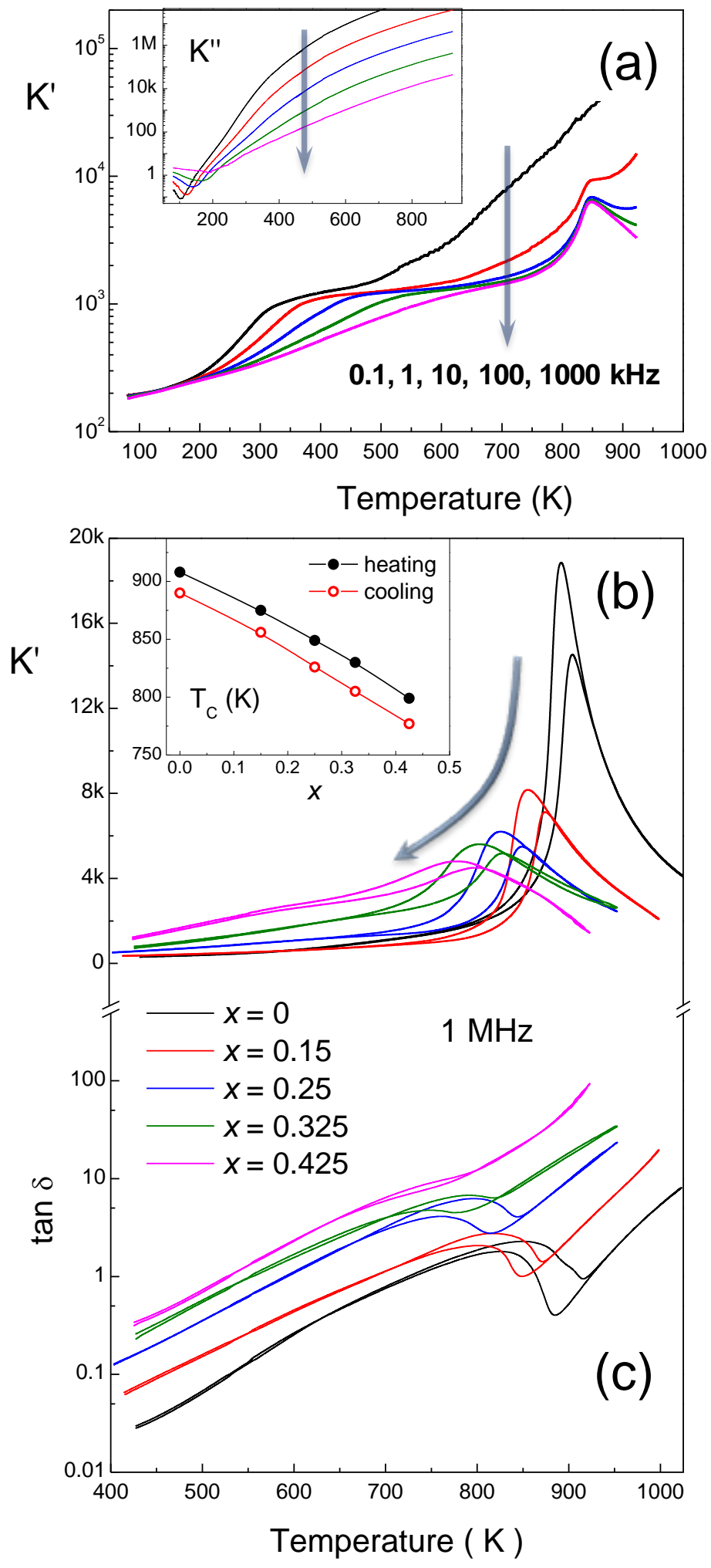